\title{
Significance of geotechnical loads on local buckling response of buried pipelines with respect to conventional practice
}

\author{
Hiva Mahdavi, Shawn Kenny, Ryan Phillips, and Radu Popescu
}

\begin{abstract}
Long-term large deformation geohazards can impose excessive deformation on a buried pipeline. The ground displacement field may initiate pipeline deformation mechanisms that exceed design acceptance criteria with respect to serviceability requirements or ultimate limit states. The conventional engineering approach to define the mechanical performance of pipelines has been based on combined loading events for in-air conditions. This methodology may be conservative, as it ignores the soil effect that imposes geotechnical loads, and also provides restraint, on buried pipelines. The importance of pipeline-soil interaction and load-transfer mechanisms that may affect local buckling of buried pipelines is not well understood. A threedimensional continuum finite element model, simulating the local buckling response of a buried pipe, using the software package ABAQUS/Standard was developed and calibrated. A comprehensive parametric study was previously conducted to investigate the effect of several parameters on local buckling response of pipelines buried in firm clay. A new strain criterion for local buckling of buried pipelines in firm clay through response surface methodology was developed. In this paper, the new criterion is compared with several existing in-air criteria to study the effect of soil restraint on the local buckling response of buried pipelines. The criterion developed in this study predicts greater characteristic critical strain capacity than in-air based criteria that highlights the influence of soil restraint.
\end{abstract}

Key words: buried pipeline, soil confinement, local buckling, continuum finite element model, elastoplastic behaviour.

Résumé : Les risques géotechniques causant de grandes déformations sur le long terme peuvent imposer des déformations excessives sur un pipeline enfouis. Les déplacements du sol peuvent initier des mécanismes de déformation dans les pipelines qui excèdent les critères de conception acceptables en lien avec les conditions d'utilisation ou les états limites ultimes. L'approche d'ingénierie conventionnelle pour définir la performance mécanique des pipelines est basée sur des événements de chargement combinés dans des conditions à l'air libre. Cette méthodologie peut être conservatrice puisqu'elle ignore les effets du sol, qui impose des charges géotechniques et aussi des restrictions sur les pipelines enfouis. L'importance de l'interaction pipeline-sol et des mécanismes de transfert de charge qui peuvent affecter le flambage local de pipeline enfouis n'est pas bien comprise. Un modèle par éléments finis à continuum en trois dimensions a été développé, et ensuite calibré, à l'aide du logiciel ABAQUS/Standard dans le but de simuler le flambage local d'un pipeline enfouis. Une étude paramétrique compréhensive a été réalisée auparavant pour étudier les effets de différents paramètres sur le comportement en flambage local de pipelines enfouis dans de l'argile ferme. Un nouveau critère de déformation décrivant le flambage local de pipelines enfouis dans de l'argile ferme a été développé par la méthodologie de la réponse de surface. Dans cet article, le nouveau critère est comparé à plusieurs critères à l'air libre existants afin d'étudier l'effet de la restriction causée par le sol sur le flambage local de pipelines enfouis. Le critère développé dans cette étude prédit une capacité de déformation caractéristique critique plus grande que les critères à l'air libre, ce qui démontre l'influence de la restriction causée par le sol. [Traduit par la Rédaction]

Mots-clés : pipeline enfouis, confinement par le sol, flambage local, modèle par élément finis à continuum, comportement élastoplastique.

\section{Background}

Buried pipelines can traverse hundreds of kilometres of terrains with varied environmental and geotechnical conditions. Along specific route corridors, the pipeline system may experience long-term large-scale ground movement because of accumulated soil deformation, such as subsidence, thaw settlement, frost heave, and slope movement (Bughi et al. 1996; Grivas et al. 1996; Glover et al. 2002; Morgan et al. 2004). Under these large ground movements, the pipelines may yield and deform excessively, thus causing local buckling or wrinkles (Bruschi et al. 1995; Honegger and Nyman 2004; Kenny et al. 2007).

To evaluate pipeline strain capacity, experimental and numerical studies generally consider only in-air boundary conditions
(Zimmerman et al. 1995; Dorey 2001). An in-air boundary condition means that the effect of soil restraint on the pipeline mechanical response is ignored. There exists significant evidence that surrounding soil provides structural support and stability (e.g., in flexible culvert design) and also involves different load characteristics (e.g., spatial and temporal variation in the soil pressure field) than imposed in conventional combined in-air loading tests (Paulin et al. 1998a; Konuk et al. 1999; Doblanko et al. 2001; Kenny et al. 2007). Few experimental or numerical studies have examined the effect of the surrounding soil on the bending performance of buried energy pipelines (Konuk et al. 1999; Popescu et al. 2002a, $2002 b$ ). The influence of hydrostatic pressure, without shear effects, on the pipe bending response has been studied (Gresnigt 1986). The key issue is that the effects of soil restraint on the 
initiation of local buckling or wrinkle development in buried energy pipelines have not been thoroughly investigated.

This study is part of a doctoral research program on local buckling behaviour of buried pipelines. The objective is to study the influence of geotechnical restraint on the local buckling response of buried pipelines. Two soil types, firm clay and dense sand, were studied. Three-dimensional continuum modelling procedures were developed, using ABAQUS/Standard, and calibrated against limited physical data on the buckling response of an unpressurized buried pipeline (Mahdavi et al. 2008). A comprehensive parametric study was conducted to examine the flexural behaviour of buried pipeline in firm clay, under combined loading (axial force, lateral force, and internal pressure) and a new critical strain criterion was developed (Mahdavi et al. 2009a). This paper includes a summary of numerical model development and calibration, and discussion on the parametric study that developed a critical strain capacity equation to assess the effects of soil restraint on the local buckling response of buried pipe. Finally, a comparison between in-air critical strain criteria and the critical strain capacity equation developed in this study, for pipelines buried in firm clay, is presented.

\section{Numerical model calibration}

There are a limited number of large-scale tests, available in the public domain, that have examined local buckling response of buried energy pipelines with parameters of relevance to the oil and gas industries. Furthermore, the available studies are typically proprietary in nature. A three-dimensional continuum numerical model was calibrated based on available full-scale tests (Konuk et al. 1999).

For the current research program, the available test data were limited to an unpressurized $203 \mathrm{~mm}$ diameter pipeline with $D / t$ of 64 (where $D$ and $t$ are diameter and thickness of the pipe, respectively), length of $5814 \mathrm{~mm}$ (2L, Fig. 1), and burial depth over diameter ratio of 4.6. A large-scale test on bending behaviour of buried pipeline in dense sand was conducted in the soil-structure testing facility at Memorial University of Newfoundland. Figure 1 demonstrates a typical experimental test layout. Two actuators were used to pull the ends of the pipeline up to $0.3 \mathrm{~m}$. The test was conducted on an unpressurized buried pipe to assess the flexural behaviour of a pipe buried in dense sand (Konuk et al. 1999). The pipe was subjected to bending through lateral displacement of the pipe ends and plastic hinges developed in the pipe during the test. The calibrated model successfully predicted the pipeline carrying load capacity, critical section location, soil deformation, and soil failure mechanism (Mahdavi et al. 2008).

While there is a considerable amount of data for in-air pipe tests, data for corresponding buried condition tests are not available. Therefore, to extend the finite element (FE) model application over a range of pipeline diameters, $D / t$ ratios, operating pressures, initial geometric imperfections, and loading conditions, the numerical model was also calibrated based on available large-scale tests performed with in-air boundary conditions. Data from several large-scale tests on the in-air local buckling behaviour of pipelines with different diameters, diameter to thickness ratios $(D / t)$, imperfection sizes, and loading conditions are available in the public domain (Zimmerman et al. 1995; Dorey 2001; Mohareb et al. 2001). In comparison with this dataset, the numerical simulations accurately captured the peak global moment, corresponding global curvature, and local buckling mode. Mahdavi et al. (2008) provide a detailed discussion of the development and calibration of the numerical model procedures to simulate the local buckling response of in-air pipe that were then used to conduct the parametric study presented herein.
Fig. 1. Plan view of full-scale bending test.

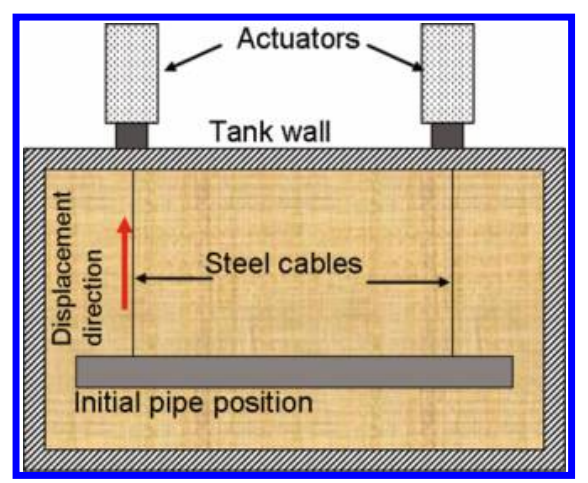

\section{Parametric study}

A comprehensive parametric study was conducted to investigate the effects of several parameters on local buckling response of buried pipelines in firm clay and dense sand. The results of this parametric study in firm clay have been also presented (Mahdavi et al. 2009a). The results of the parametric study in dense sand are currently under review and will be discussed in a future publication. The statistical design of experiments (DOE) methodology was applied to establish an efficient parametric study plan (Montgomery 2005). The main advantage of the DOE methodology is that the effect of each parameter and of any possible interaction between parameters on the response can be detected through a limited number of runs. For the firm clay, six parameters were selected to study their effects on the local buckling response of buried pipelines. These parameters were chosen based on the results of numerical and experimental studies available in the open literature.

The selected parameters are: pipeline diameter $(D)$, pipeline diameter to wall thickness $(t)$ ratio denoted $D / t$, pipeline material grade, the ratio between hoop stress $\left(\sigma_{\mathrm{h}}\right)$ due to internal pressure and pipeline yield stress (SMYS) denoted $\beta$, the ratio between the axial force $(N)$ and characteristic plastic axial force resistance $\left(S_{\mathrm{p}}\right.$ from DNV 2010) denoted $\alpha$, and the ratio between pipeline burial depth (from the ground surface to the pipeline springline level, $H$ ) and diameter $(D)$ denoted $H / D$. Overall, 45 numerical analyses have been conducted to complete the parametric study. The most popular response surface methodology, central composite design (CCD) was used for the purpose of the parametric study (Mahdavi et al. 2009a). The results of two examples of the 45 analyses are briefly discussed later in this paper.

\section{Numerical model characteristics}

Numerical modelling procedures were developed, using the FE software ABAQUS/Standard, to simulate the bending and local buckling response of a buried energy pipeline (Fig. 2). The pipeline length $(L)$ and the surrounding soil dimensions in front (denoted as a), beneath (denoted as b), and behind (denoted as c) the pipeline varied proportionally with the pipeline diameter (Table 1). The selected analysis dimensions completely accommodated the soil failure mechanism due to pipeline movement. To reduce the computational effort required, symmetric boundary conditions were defined at the pipeline midsection, which is indicated in Fig. 2. The displacement degrees of freedom along the $Y$-axis and rotation around $Z$ - and $X$-axes are restrained.

The current study examines the effect of geotechnical restraint on the local buckling response of a buried pipeline. The study does not examine mechanisms or conditions that trigger large deformation ground movement. Lateral displacement of $1-1.5 D$ was applied at the end of the pipe (reference point, RP, in Fig. 2). The pipe is extended outside of the soil to provide a larger lever arm to bend the pipe. Linear, general-purpose, shell-reduced integration elements (S4R) with finite membrane strains were used to discretize 
Fig. 2. Numerical model geometry.

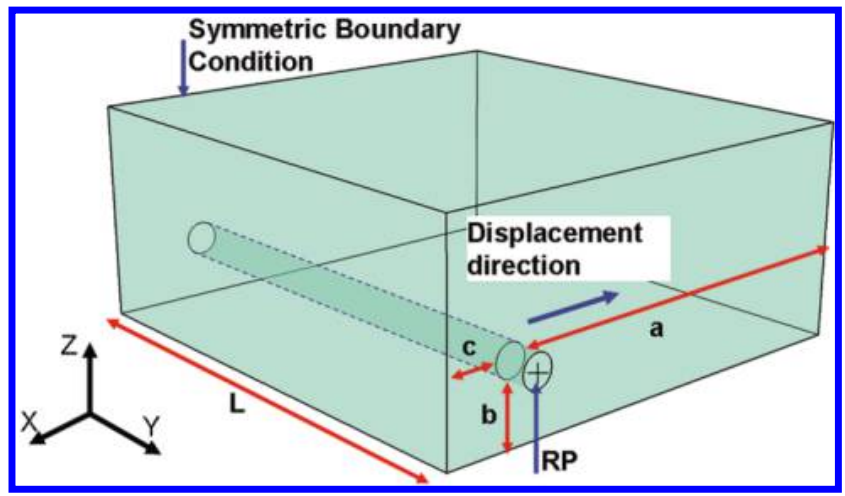

Table 1. Approximate dimensions of the numerical models.

\begin{tabular}{lllll}
\hline$D(\mathrm{~m})$ & $a / D$ & $b / D$ & $c / D$ & $L / D$ \\
\hline 0.324 & 6 & 1 & 1.5 & 9 \\
0.762 & 5 & 1 & 0.7 & 9 \\
\hline
\end{tabular}

the pipeline. The soil was discretized with three-dimensional solid continuum elements (C3D8R, ABAQUS v6.5.1 user and theory manuals. Geometric imperfections were not prescribed along the pipeline. However, nonuniform distribution of external soil pressure along the pipe acts as an imperfection and triggers local buckling.

The geomechanical parameters of the firm clay used for the numerical model are presented in Table 2 . The undrained shear strength is selected based on reasonable value measured for firm clay in the literature to provide enough restraint to buckle the pipeline (Terzaghi and Peck 1967; Kulhawy and Mayne 1990). Young's modulus for firm clay and contact properties are defined through model calibration based on available large-scale tests conducted on a pipeline buried in firm clay (Paulin et al. 1998a, 1998b). For normally consolidated clays, the undrained shear strength (Su) linearly increases with depth. However, in this paper overconsolidated clay is analysed, where the increase of Su with depth is relatively slow, and can be taken to be constant for the dimensions of the analysis model. The von-Mises constitutive model was used to simulate firm clay undrained behaviour.

A piecewise elastoplastic constitutive model was used for the pipeline material. The stress-strain relationship of the pipeline was calculated from the Ramberg-Osgood formula (Walker and Williams 1995). The pipeline Young's modulus (E) was $205 \mathrm{GPa}$.

The pipeline-soil interface was simulated using the contact surface approach implemented in ABAQUS/Standard. This approach allows for separation and sliding with finite amplitude and arbitrary rotation of the contact surfaces. The classical isotropic Coulomb friction model with a fixed adhesion limit was used to simulate the interaction between the pipeline and the soil. ABAQUS provides an option to limit the shear stress at the interface irrespective of the mobilized normal stress. The large friction coefficient of 1 was adopted so that the interface was controlled primarily by the adhesion limit between the pipeline and soil (Honegger and Nyman 2004).

\section{Postprocessing and discussion on sample analyses}

For each analysis, the pipeline strain, pipeline bending moment, pipeline global curvature, and pipeline factor of ovalization is assessed. The pipeline critical strain $\left(\varepsilon_{\text {crit }}\right)$ is calculated by averaging the total axial compressive strain at extreme fiber of the pipeline along a certain gauge length, corresponding to the peak moment increment (Fig. 3). The critical strain is measured along two gauge lengths of $D$ and $D / 3$.

The bending moment in a given section of the pipeline (sectional moment) is calculated by integrating the bending moment
Table 2. Soil mechanical parameters used for the numerical model.

\begin{tabular}{lllll}
\hline $\begin{array}{l}\text { Type of } \\
\text { soil }\end{array}$ & $\begin{array}{l}\text { Undrained shear } \\
\text { strength, } S_{\mathrm{u}}(\mathrm{kPa})\end{array}$ & $\begin{array}{l}\text { Young's } \\
\text { modulus, } \\
E_{\mathrm{s}}(\mathrm{kPa})\end{array}$ & $\begin{array}{l}\text { Poisson's } \\
\text { ratio, } v\end{array}$ & $\begin{array}{l}\text { Interface } \\
\text { friction } \\
\text { coefficient }\end{array}$ \\
\hline Firm clay & 100 & 10000 & 0.49 & 1 \\
\hline
\end{tabular}

Fig. 3. Critical strain definition.

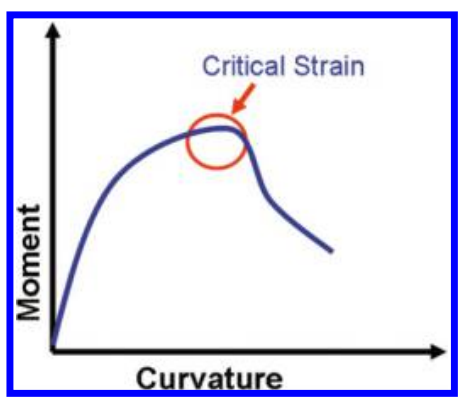

Table 3. Numerical model characteristics of the two examples.

\begin{tabular}{lllllll}
\hline $\begin{array}{l}\text { Analysis } \\
\text { number }\end{array}$ & $D(\mathrm{~m})$ & $\mathrm{D} / \mathrm{t}$ & $\begin{array}{l}\text { Pipeline } \\
\text { grade }\end{array}$ & $\sigma_{\mathrm{h}} / \mathrm{SMYS}$ & $N / S_{\mathrm{p}}$ & $H / D$ \\
\hline 1 & 0.324 & 51 & $\mathrm{X} 52$ & 0 & 0.25 & 2 \\
2 & 0.762 & 92 & X52 & 0.8 & 0.25 & 4 \\
\hline
\end{tabular}

Fig. 4. Deformed pipe-soil model — analysis 1.

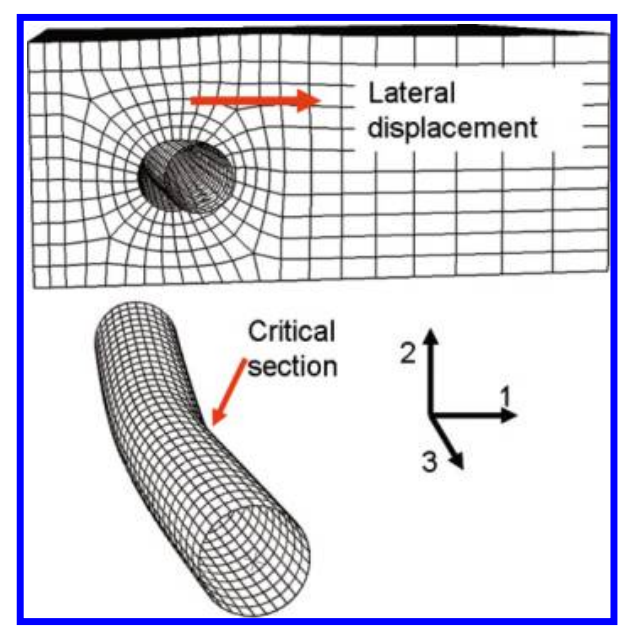

caused by axial forces of the circumferential elements about the bending axis of the section. The bending axis of the pipeline section is approximated based on the deformed pipeline.

The ovalization factor was calculated from eq. [1] in which $D_{\max }$ and $D_{\min }$ are the maximum and minimum measured diameters of the pipeline, respectively. The factor of ovalization approximates a pipeline section out of roundness.

[1] $f=\frac{D_{\max }-D_{\min }}{D_{\max }+D_{\min }}$

Two analyses, for a pressurized case (number 1, Table 3), are selected as illustrative examples for discussion on the typical mechanical response and observations. The buried pipeline was laterally displaced and developed spatial variation in the applied soil pressure load. Further lateral pipe displacement caused increased bending or pipe curvature to develop that led to a local buckling response. 
Fig. 5. Bending moment versus local strain at critical section — analysis 1 .

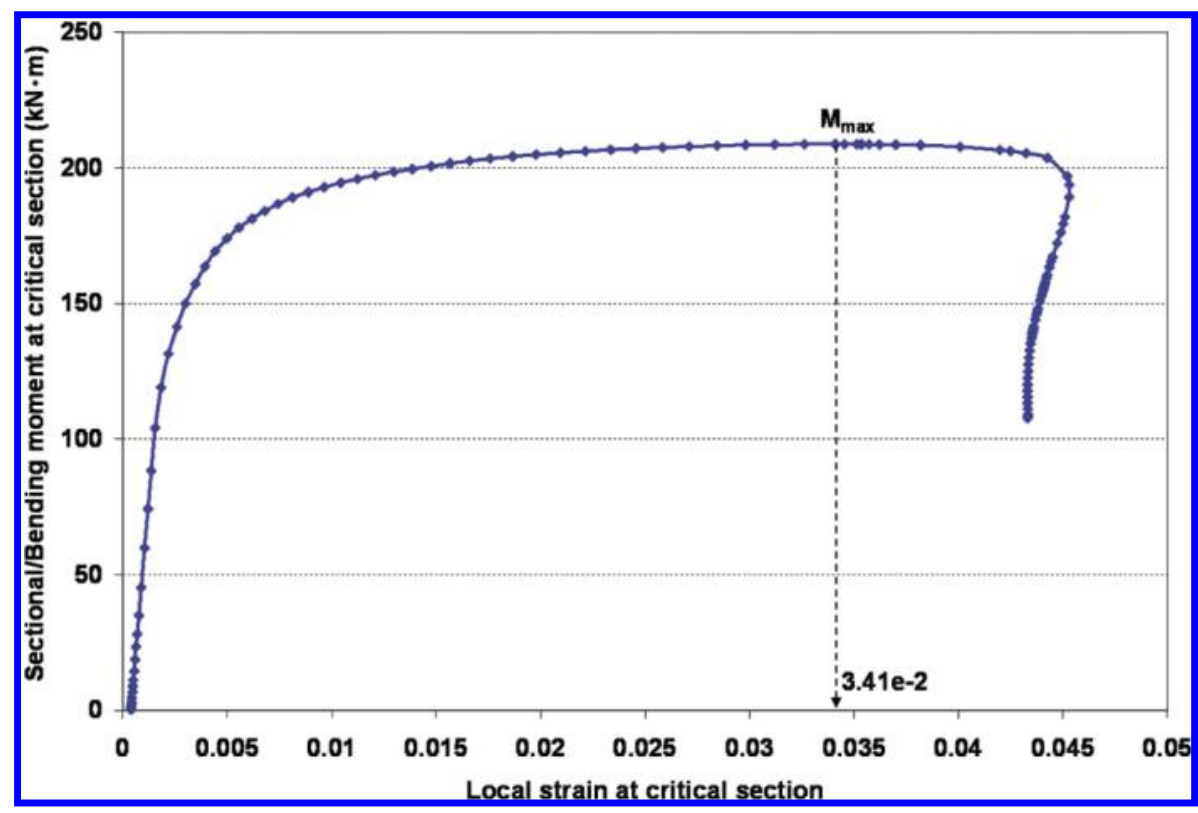

Fig. 6. Factor of ovalization along the pipeline at the peak moment increment and location of peak ovalization on a deformed pipeline analysis 1.

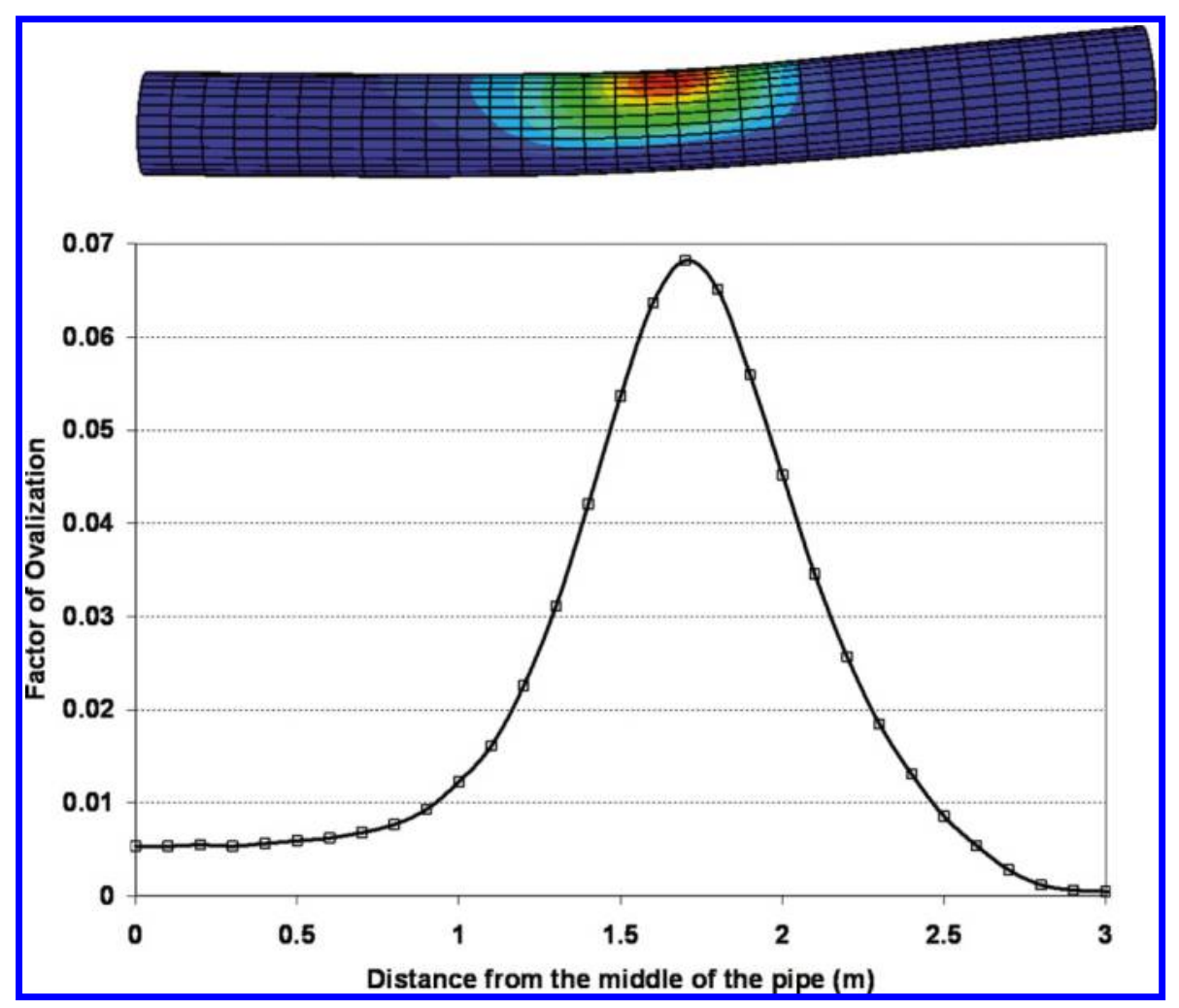

A typical pipe-soil interaction response with deformed geometry is shown in Fig. 4. For the unpressurized case (analysis 1), the pipeline buckled inward and exhibited the classical diamond mode pattern for local buckling. The critical section, as indicated, is 1.4-1.5 $\mathrm{m}$ away from the pipeline end. The pipeline bending moment versus local strain, at the pipe critical section, is presented in Fig. 5 where the critical strain (i.e., pipe curvature) corresponding with the peak moment is also indicated. The variation of the pipe ovalization factor, at the peak moment increment $\left(M_{\max }\right)$ is shown in Fig. 6 . The distribution of plastic strain in the pipe wall is also illustrated, at the top of the diagram, where correspondence is observed between the location of highest factor of ovalization associated with the critical section and the strain localization. During this loading event, at the peak bending moment increment $\left(M_{\max }\right)$, the soil failure mechanism exhibits a passive wedge extending toward the surface that causes noticeable surface heave as indicated by the soil plastic strain contours (Fig. 7). 
Fig. 7. Contours of plastic strain magnitude in soil for analysis 1 at maximum bending moment.

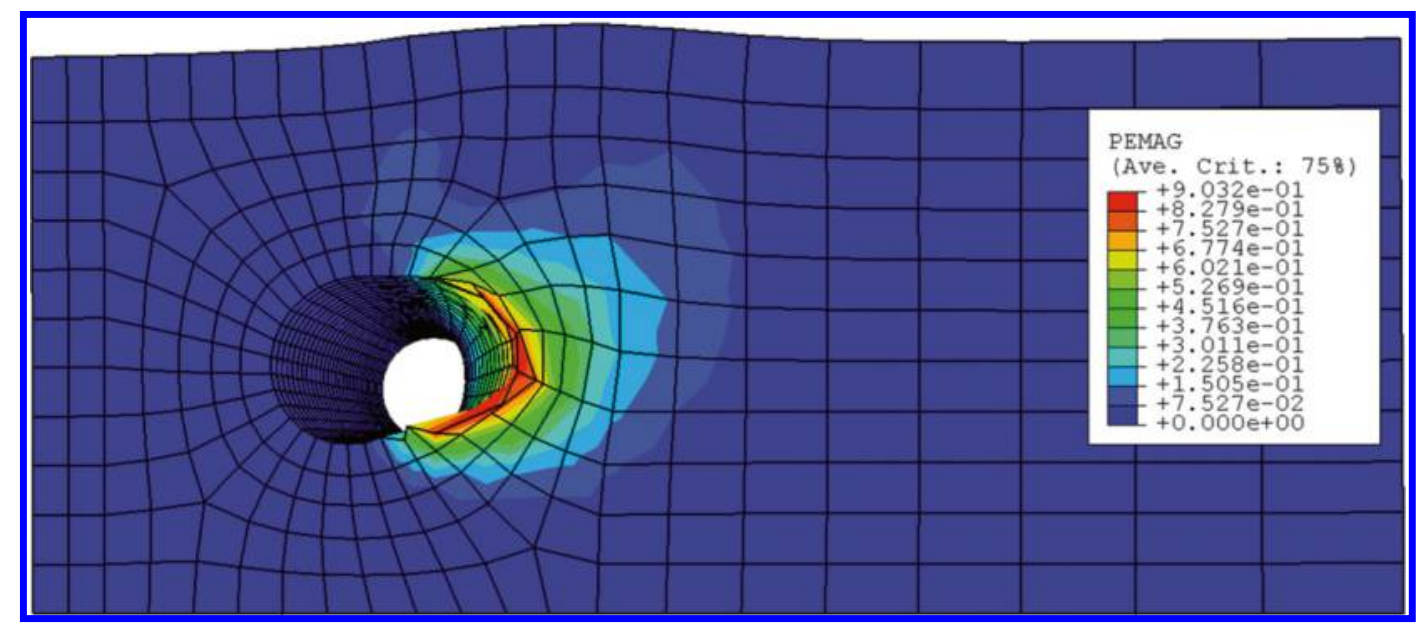

As shown in Fig. 8, for the pressurized pipe analysis case, an outward bulge type mode was observed that was consistent with in-air based research results, (Zimmerman et al. 1995). The pipe critical section is $1.8 \mathrm{~m}$ away from the pipeline end as indicated. The pipeline bending moment versus local strain, at the pipe critical section, is presented in Fig. 9 with the critical strain corresponding to peak sectional moment as indicated. The variation of pipe ovalization factor, at the peak moment increment $\left(M_{\text {max }}\right)$ is shown in Fig. 10. The distribution of plastic strain in the pipe wall is also illustrated, at the top of the diagram, where correspondence is observed between the location of highest factor of ovalization associated with the critical section and the strain localization. Local buckling evolves through the formation and development of a series of wrinkles around the critical section, with one or two dominant wrinkles. This is consistent with other studies examining the local buckling response for in-air and buried pipelines (Popescu et al. 2002a; Kyriakides and Corona 2007; Fatemi and Kenny 2012). In Fig. 10, the two outward bulge patterns are visible with the corresponding ovalization factors and strain localization shown. The magnitude and distribution of soil plastic strain, corresponding to the peak bending moment increment, is illustrated in Fig. 11. Because of larger cover depth than analysis 1, the soil fails locally (punching type mechanism) and flows around the pipe without noticeable soil surface heave.

A comparison between these two analyses shows that the soil failure mechanism depends on the pipeline burial depth ratio $(H / D$, passive wedge or punching type mechanism). The buckling modes (inward or outward) depend primarily on the pipeline internal pressure ratio. More details on the parametric study results, such as (i) which parameters have the most significant effect on critical buckling strain, and (ii) how each factor interacts with the others, are discussed later in this paper.

\section{New critical strain criterion}

Design-Expert software version 6 was used to evaluate the results of the parametric study (Mahdavi et al. 2009a). Response surface methodology (RSM) was used to develop the critical strain $\left(\varepsilon_{\text {crit }}\right)$ equations. RSM approximates the response through regression analysis (Montgomery 2005). A new critical strain criterion for the critical strain $\left(\varepsilon_{\text {crit }}\right)$ of a buried pipeline subject to combined load state was developed. Details of equation development have been previously presented in Mahdavi et al. (2009a). This
Fig. 8. Deformed model at the pipeline peak bending moment increment - analysis 2 .

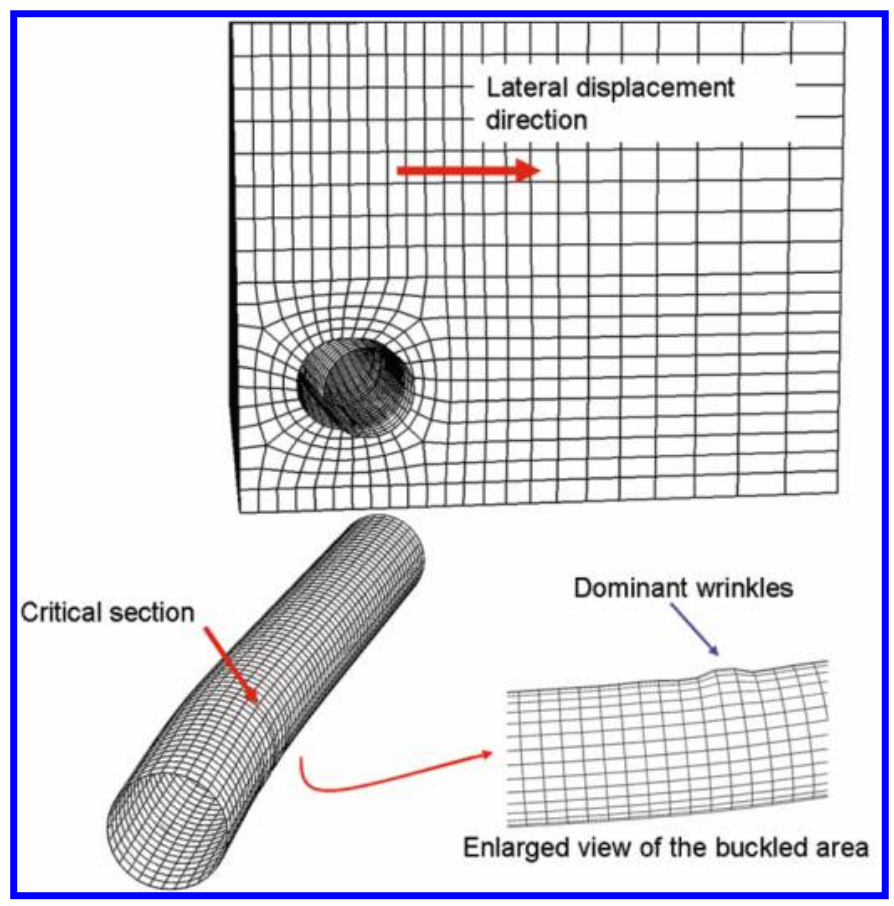

study has defined the critical buckling strain as the total axial compressive strain corresponding to the peak moment measured over two different gauge lengths of $D / 3$ and $1 D$ along the pipeline extreme compressive fiber. Equation [2] provides the critical strain of buried pipeline along the gauge length of $D / 3$. The primary goals are to identify the statistically significant parameters and provide a quantitative basis to assess the effects of soil restraint on the local buckling response of buried pipe in comparison with in-air strain capacity estimates. For eq. [2], pipe diameter is the only dimensional term and is defined by metres. Also, it should be mentioned that the equation is developed to fit the response within the ranges of parameters used in this study as shown in Table 4. Extrapolations outside these ranges are not recommended.

$$
\begin{aligned}
& {[2] \quad \begin{array}{llllllll}
\varepsilon_{\text {crit }} & 0.11872 & 0.01037 D & 2.0205 \times 10^{3}(D / t) & 4.51597(\mathrm{SMYS} / E) & 0.13103 \beta & 6.62323 \times 10^{3} \alpha & 1.18768 \times 10^{5}(D / t)^{2}
\end{array}} \\
& 6.54164 \times 10^{4}(D / t) \beta \quad 18.95806(\text { SMYS/E) } \beta \quad 0.031132 \beta \alpha
\end{aligned}
$$


Fig. 9. Bending moment versus local strain at critical section — analysis 2 .

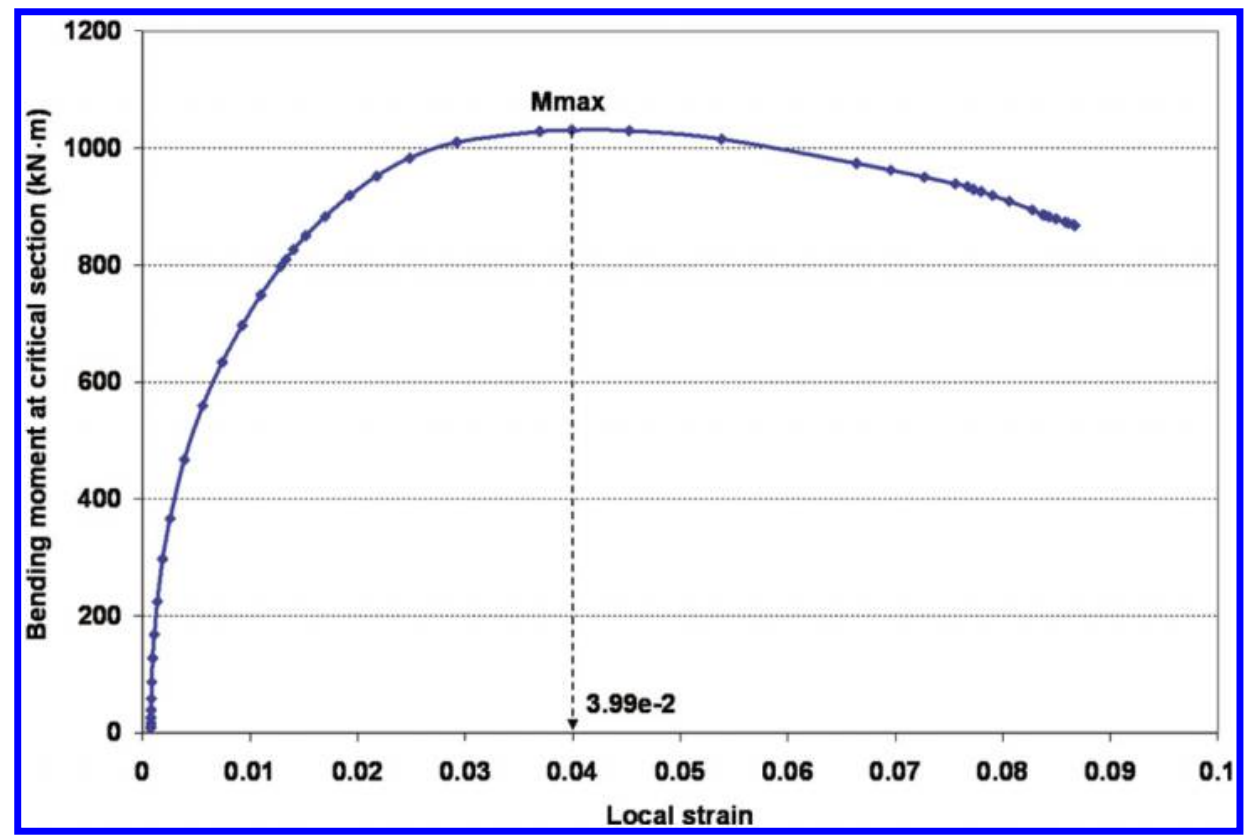

Fig. 10. Variation of factor of ovalization along the pipeline at peak moment increment and location of peak ovalization on a deformed pipeline - analysis 2 .

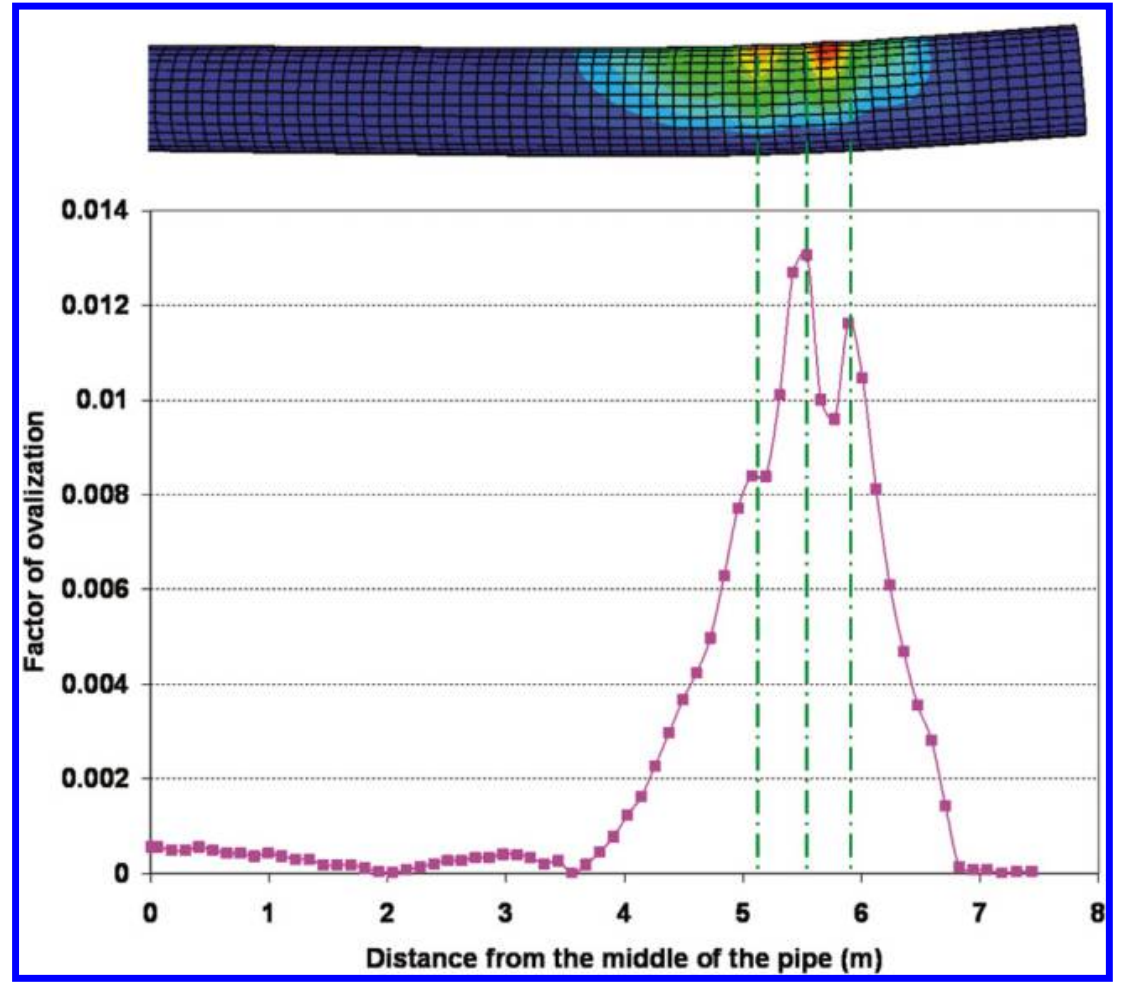

According to statistical analyses, $D, D / t$, SMYS/E, $\beta,(D / t)^{2}$, and the interaction effects of $D / t$ and $\beta$, SMYS/E and $\beta$, and finally $\beta$ (or SMYS $/ \sigma_{\mathrm{h}}$ ) and $\alpha$ (or $N / \mathrm{S}_{\mathrm{P}}$ ) were recognized as the significant model terms. The model term contributions to the response are not homogeneous. According to conducted statistical analyses, the terms hoop stress ratio $(\beta)$ and $D / t$ ratio have the largest contribution to the response. The terms' contributions to the response (critical strain) are discussed later in this paper. Generally, the current study shows that the critical strain decreases as $D, D / t$, and pipeline material grade increase. Also, the critical strain increases with internal pressure. These results are in agreement with other studies, such as Dorey (2001) and Fatemi et al. (2008) among others. The variation of the critical strain with the axial force ratio $(\alpha)$ depends on the internal pressure. The equation predicts that $H / D$ from 2 to 4 was not as significant for critical strains as the other parameters for pipes in firm clay as sufficient soil resistance was available to initiate buckling in the pipe (Mahdavi et al. 2009a).

Further examination of the effects of embedment ratio $(H / D)$ on bending behaviour of a pipeline over the $H / D$ from 1 to 8 was studied through the numerical approach. Several analyses on both unpressurized and pressurized pipelines with $H / D$ from 1 
Fig. 11. Contours of plastic strain magnitude for analysis 2 at maximum bending moment.

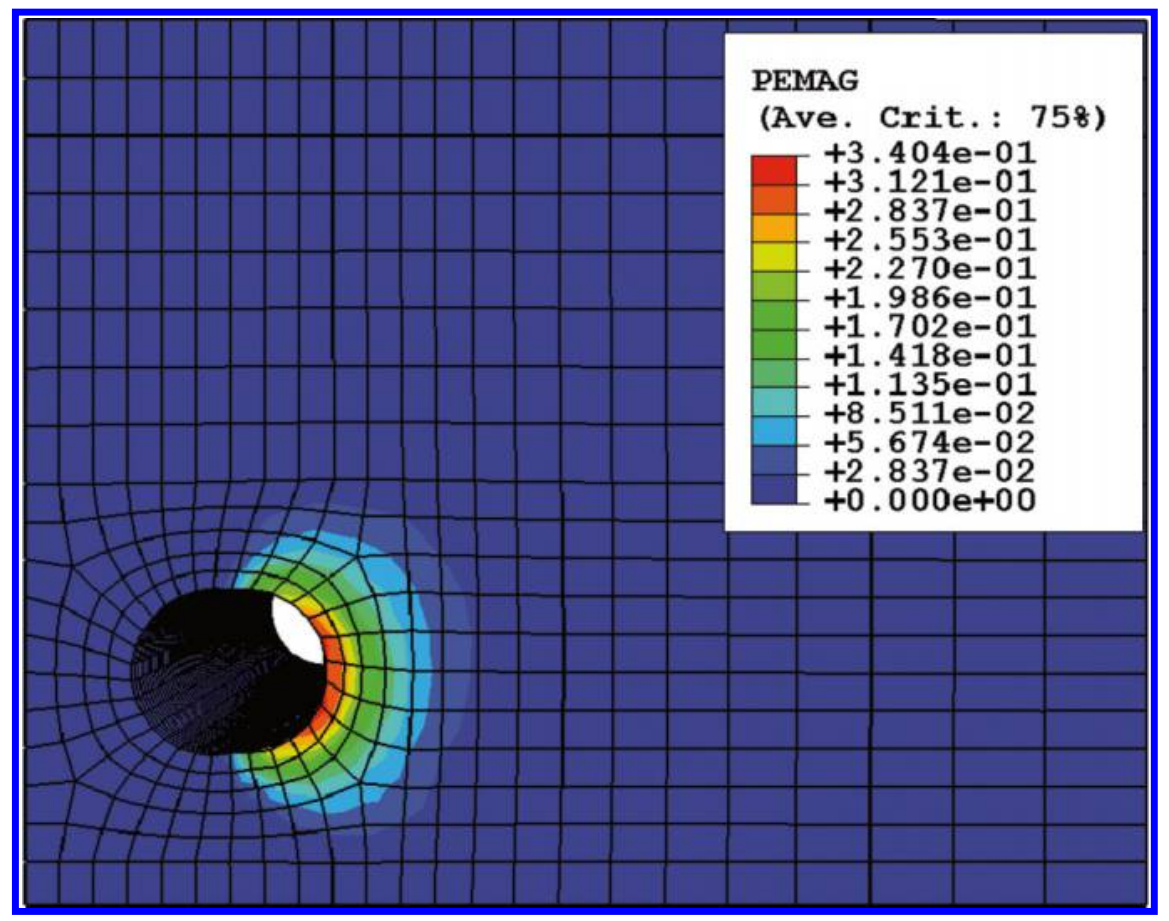

Table 4. Parametric study factors.

\begin{tabular}{lll}
\hline Factor & Low level & High level \\
\hline$D(\mathrm{~m})$ & 0.324 & 0.762 \\
$D / t$ & 51 & 92 \\
Pipeline grade & 52 & 70 \\
$\beta=\sigma_{\mathrm{h}} / S M Y S$ & 0 & 0.8 \\
$\alpha=N / S_{\mathrm{p}}$ & 0.25 & 0.56 \\
$H / D$ & 2 & 4 \\
\hline
\end{tabular}

to 8 were conducted. The study by Mahdavi et al. (2009b) provides further results and detailed discussion. As H/D increases the soil resistance against a pipeline lateral displacement increases. For a shallower $H / D$ of 1 and 2, the surrounding soil fails in the form of a passive wedge initiating in front of the pipe and extending toward the surface with noticeable soil surface heave. As the burial depth increases, the soil fails locally and flows around the pipe. Changes in the soil failure mechanism affect the stress distribution at the contact between pipeline and soil. Therefore, the amount of stress that can be transferred changes. Also the location of the critical section and the global curvature vary, which can change the bending moment along the pipeline. The study concluded that although $H / D$ is not significant from 2 to 4 depending on the pipeline properties and loading conditions, this ratio affects the soil failure mechanism and the buckling response of the pipeline at different $H / D$ values (Mahdavi et al. 2009b).

\section{Comparison of buried pipe curvature response with in-air observations}

A substantial volume of literature exists on the local buckling response of pipelines that has included analytical, experimental, and numerical modelling investigations (e.g., Sherman 1976; Murphey and Langner 1985; Gresnigt 1986; Dorey 2001; Suzuki et al. 2006; Fatemi et al. 2008, 2010; Fatemi and Kenny 2011, 2012). Key factors influencing the local buckling response and compressive strain capacity include pipe body geometric imperfections, $D / t$ ratio, internal pressure, axial load, material properties, characteristics of the stress-strain relationship and imperfections as- sociated with the field joining process of pipe joints. Early studies characterized the compressive strain limits in terms of physical geometric factors, such as the $D / t$ ratio (Sherman 1976; Murphey and Langner 1985). Through other investigations, the significance of additional parameters was established (Gresnigt 1986; Bruschi et al. 1995; Zimmerman et al. 1995; Vitali et al. 1999; Dorey 2001), however, there is no industry-wide consensus on a single functional expression for the design acceptance criteria for compressive strain limits due to local buckling. The common thread is that the equations have been developed based on experimental and numerical studies for pipeline segments with respect to in-air boundary conditions (i.e., did not account for the effects of the surrounding soil). In general, the critical strain limit is associated with the curvature at peak moment. In this study, the compressive strain limit functions developed by Dorey (2001), Gresnigt (1986), and Zimmerman et al. (1995) are used to assess the numerical simulations conducted in this study examining the local buckling response of pipe segments with in-air boundary conditions.

Zimmerman et al. (1995) developed a semiempirical critical strain equation through numerical simulation and assessment of existing physical data. A parametric study was conducted on a 0.610 m diameter pipe with $D / t$ ratio of $30-100$, and material grade of 483-621 MPa. As shown in Table 5, the effect of $D / t$ and internal pressure was included in the critical strain equation for a material hardening parameter of 30.

Dorey (2001) also conducted a numerical parametric study to develop a mathematical expression defining the pipe compressive strain capacity. The parametric study evaluated the mechanical response of a $0.762 \mathrm{~m}$ diameter pipe with $D / t$ ratio of $50-90$ and material grade of 360-550 MPa. A simple, idealized discrete, blister-type imperfection was used to trigger local buckling mechanisms with imperfection amplitudes of $2 \%-30 \%$ of the wall thickness. Studies have indicated this approach does not account for mode response or mechanisms that may evolve during the transition from prebuckling (i.e., bifurcation) through the postbuckling regime (Peek 2000; Kyriakides and Corona 2007; Fatemi and Kenny 2011, 2012). Mathematical expressions were developed by Dorey (2001), through bilinear regression analysis, to define the compressive strain capacity of plain pipe and girth welded pipe 
Table 5. Several in-air based equations.

\begin{tabular}{|c|c|}
\hline Source & Equations \\
\hline Zimmerman et al. (1995) & $\varepsilon_{\text {cr }} \quad 8.5\left(\frac{t}{D}\right)^{2} \quad 34\left(120 \quad \frac{D}{t}\right)\left(\frac{\sigma_{\mathrm{h}}}{E}\right)^{2} \quad 0.0021$ \\
\hline Dorey (2001) & $\begin{array}{l}\text { Rounded material properties } \\
\varepsilon_{\mathrm{cr}}\left(\frac{2.9398}{D / t}\right)^{1.5921}\left(\begin{array}{ll}1 & 0.8679 \frac{p}{p_{\mathrm{y}}}\end{array}\right)^{1}\left(\frac{E}{\sigma_{\mathrm{y}}}\right)^{0.8542}\left[\begin{array}{ll}1.2719 & \left(\frac{\mathrm{imp}}{100}\right)^{0.1501}\end{array}\right]\end{array}$ \\
\hline & $\begin{array}{l}\text { Yield plateau material properties } \\
\varepsilon_{c r} \quad 40.4\left(\frac{t}{D}\right)^{2}\left(\begin{array}{ll}1 & 0.906 \frac{p}{p_{\mathrm{y}}}\end{array}\right)^{1}\left(\frac{E}{\sigma_{\mathrm{y}}}\right)^{0.80}\left[1.12\left(\frac{\mathrm{imp}}{100}\right)^{0.15}\right]\end{array}$ \\
\hline CSA Z662 (CSA 2003) & $\begin{array}{llll}\varepsilon_{\text {cr }} & 0.5 \frac{t}{D} & 0.0025 & 3000\left(\frac{\left(P_{\mathrm{i}} P_{\mathrm{e}}\right)}{2 t E_{\mathrm{s}}} D\right)^{2} \text { for } \quad \frac{\left(P_{\mathrm{i}} \quad P_{\mathrm{e}}\right)}{2 t \sigma_{\mathrm{y}}} D<0.4 \\
\varepsilon_{\text {cr }} & 0.5 \frac{t}{D} & 0.0025 & 3000\left(\frac{0.4 F y}{E_{\mathrm{s}}}\right)^{2} \text { for } \quad \frac{\left(P_{\mathrm{i}} \quad P_{\mathrm{e}}\right)}{2 t \sigma_{\mathrm{y}}} D \geq 0.4\end{array}$ \\
\hline
\end{tabular}

Note: $p / p_{\mathrm{y}}$, internal pressure ratio; imp, initial imperfection amplitude as a percent of wall thickness; $P_{\mathrm{e}}$, minimum external hydrostatic pressure.

Fig. 12. Comparison of the moment-curvature relationship.

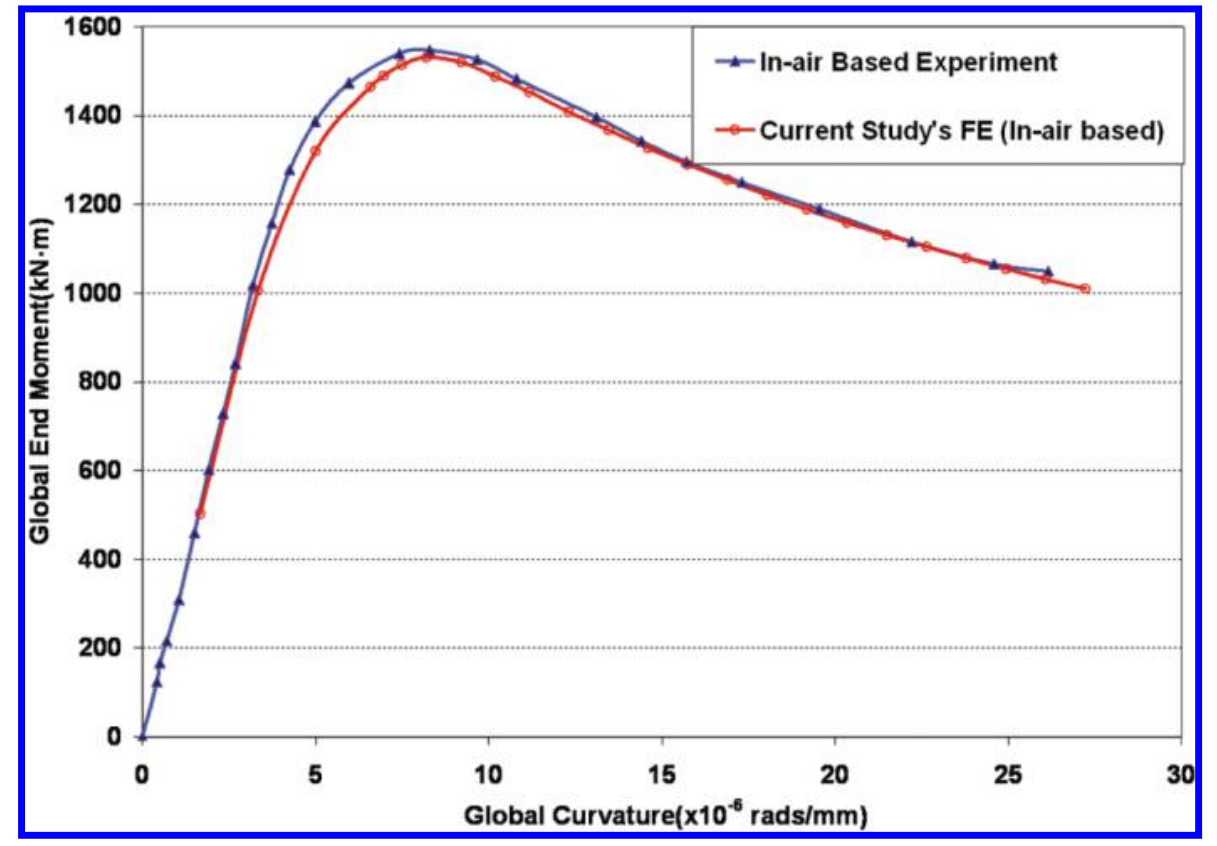

Table 6. Numerical and experimental results comparison (in-air based).

\begin{tabular}{lcc}
\hline Experiment ID & $\left(\frac{M_{\max }^{\exp }}{M_{\max }^{\mathrm{FE} \text { in-air }}}\right)^{a}$ & $\left(\frac{\varepsilon_{\text {crit }}^{\exp }}{\varepsilon_{\text {crit }}^{\mathrm{FE} \_ \text {in-air }}}\right)^{b}$ \\
\hline CP80N_2 & 1.01 & 1.086
\end{tabular}

${ }^{a}$ Experimental maximum bending moment at the pipe end over the numerical maximum bending moment.

${ }^{b}$ Experimental critical strain over the numerical critical strain (in-air based).

that accounted for the characteristic shape of the stress-strain relationships (Table 3). A stress-strain relationship with a smooth transition from yield through strain hardening was defined as a roundhouse curve (i.e., Ramberg-Osgood shape) and yield plateau was associated with discontinuous yielding (i.e., Lüder's plateau).

Based on the study conducted by Gresnigt (1986), the Canadian Standards Association (CSA 2003) adopted a critical strain equation that includes the effect of $D / t$, difference between internal and external pressure and material yield strength (Table 5). The critical strain equations, presented in Table 5, have been established within a specific range of parameters, test conditions, and simulation procedures.

Before directly comparing in-air based equations with the current study's results, an in-air based FE model (developed and calibrated based on one of Dorey's in-air based experiments) is compared with the selected in-air based critical strain equations (Table 5). The objective of this comparison is to provide an idea of the residual errors between the FE model for in-air pipe developed in this study and in-air based critical strain equations. Next, the effect of the surrounding soil is assessed by comparing the FE results for pipe in air with those for buried pipe. This last comparison is based on numerical models developed in this study. The in-air based equations (Table 5) and the current study's equation (eq. [2]) are then directly compared for several pressurized and unpressurized cases. One test from the study by Dorey (2001) is selected for the current study's in-air based FE model calibration. The test is conducted on a plain segment of pipe with an outside diameter of $0.762 \mathrm{~m}, \mathrm{D} / \mathrm{t}$ of 92 , grade of $\mathrm{X} 70$, and internal pressure ratio of 0.8 (Dorey 2001). 
Table 7. Numerical results comparison with critical strain criteria.

\begin{tabular}{|c|c|c|c|c|c|}
\hline \multirow[b]{2}{*}{ Experiment ID } & \multicolumn{2}{|l|}{$\begin{array}{l}\frac{\varepsilon_{\text {crit }}^{\text {Dorey }}}{} \\
\varepsilon_{\text {crit }}^{\text {Ecin-air }} \\
\end{array}$} & \multirow{2}{*}{$\frac{\varepsilon_{\text {crit }}^{\text {Zimmerman }}}{\varepsilon_{\text {crit }}^{\mathrm{FE} \text { innair }}}$} & \multirow{2}{*}{$\frac{\varepsilon_{\text {crit }}^{\mathrm{CSA}}}{\varepsilon_{\text {crit }}^{\mathrm{FE} \text { in-air }}}$} & \multirow[b]{2}{*}{$\frac{\varepsilon_{\text {crit }}^{\text {current-study }}}{\varepsilon_{\text {crit }}^{\text {FE in-air }}}$} \\
\hline & $i m p=2 \%$ & $i m p=30 \%$ & & & \\
\hline CP80N_2 & 3.36 & 1.699 & 1.75 & 1.39 & 8.45 \\
\hline
\end{tabular}

The in-air based FE model is developed using the same geometry, material properties, and boundary conditions as this benchmark test case. A blister-type imperfection with an amplitude of $12 \%$ (thickness percentage) is defined in the numerical model to trigger local buckling. The relationship between global bending moment and global curvature as predicted within this study in comparison with the results of Dorey (2001) is illustrated in Fig. 12 and summarized in Table 6. There is excellent correspondence between the numerical simulations of this study and the benchmark physical test of Dorey (2001) throughout the elastic, peak moment, and postbuckling response. The in-air based FE model, developed in this study, was validated against five other physical tests (Dorey 2001; Mohareb et al. 2001), but the results are not presented in this paper (Mahdavi et al. 2008). In general, the in-air based FE model closely predicts the overall behaviour of the experimental test and the critical strain as the point of local buckling initiation. On this basis, it can be concluded that the FE procedures developed in this study, for in-air boundary conditions, are consistent with the experimental observations with respect to the global moment-curvature relationship, peak moment amplitude, critical associated with the curvature at peak moment, and local buckling mode response.

A comparison of the FE results with the critical strain equations from the three independent studies (Zimmerman et al. 1995; Dorey 2001; CSA 2003) is presented in Table 7. The results demonstrate variability in the predicted compressive strain capacity limits for the same input parameters, which is due to a number of factors in the development of the specific equation based on different test parameters. Thus, model uncertainty and potential bias exist in the predicted strain capacity estimates. For example, the plain pipe strain capacity equations developed by Dorey (2001), based on physical tests conducted at the University of Alberta, was assessed using third-party and reported the coefficient of variation ranging from $0.1 \%$ to $56 \%$. The uncertainty was primarily associated with the initial geometric imperfection and shape of the material stress-strain relationships (Dorey 2001). Recent studies (Fatemi et al. 2008, 2010; Fatemi and Kenny 2011, 2012) have shown other factors, such as bifurcation modes, characteristics of initial geometric imperfections, and boundary conditions may also explain this variability and uncertainty.

Comparison between the critical strain equations, developed in this study using FE procedures, for buried pipe with in-air based is presented in Table 7. A minimum axial force ratio of $25 \%$ and $H / D$ of 2 are examined. The results indicate that soil restraint increases the pipeline critical strain based on the pipe curvature profile. Although model uncertainty exists in the prediction of the pipe critical strain for in-air boundary conditions, the results suggest that the soil restraint influences the pipe critical strain estimate by a factor of 8 , which emphasizes the dominant soil restraint effect. This does not mean the pipe strain capacity itself has increased, but illustrates the relative significance of the surrounding soil to influence pipe strain capacity, as measured by pipe curvature, and the sectional response (i.e., ovalization) of the buried pipe in comparison with in-air boundary conditions.

Fifteen unpressurized and 15 pressurized cases are chosen to compare in-air based critical strain with continuum pipe-soil interaction model's strain. The comparative analysis presented provides only trends in the observations rather than absolute values. The parameters examined in this study are summarized in
Table 8. Unpressurized cases.

\begin{tabular}{rlllll}
\hline & $D(\mathrm{~m})$ & $D / t$ & Grade & $N / S_{\mathrm{p}}$ & $\mathrm{H} / \mathrm{D}$ \\
\hline 1 & 0.324 & 51 & $\mathrm{X} 52$ & 0.25 & 2 \\
2 & 0.324 & 51 & X52 & 0.56 & 4 \\
3 & 0.324 & 92 & X52 & 0.25 & 4 \\
4 & 0.324 & 92 & X52 & 0.56 & 2 \\
5 & 0.324 & 92 & X70 & 0.25 & 2 \\
6 & 0.324 & 92 & X70 & 0.56 & 4 \\
7 & 0.543 & 71.5 & X60 & 0.405 & 3 \\
8 & 0.762 & 51 & X52 & 0.25 & 4 \\
9 & 0.762 & 51 & X52 & 0.56 & 2 \\
10 & 0.762 & 51 & X70 & 0.25 & 2 \\
11 & 0.762 & 51 & X70 & 0.56 & 4 \\
12 & 0.762 & 92 & X52 & 0.25 & 2 \\
13 & 0.762 & 92 & X52 & 0.56 & 4 \\
14 & 0.762 & 92 & X70 & 0.25 & 4 \\
15 & 0.762 & 92 & X70 & 0.56 & 2 \\
\hline
\end{tabular}

Table 9. Pressurized cases.

\begin{tabular}{rllllll}
\hline & $D(\mathrm{~m})$ & $D / t$ & Grade & $\sigma_{\mathrm{h}} /$ SMYS & $N / S_{\mathrm{p}}$ & $H / D$ \\
\hline 1 & 0.324 & 51 & X52 & 0.8 & 0.25 & 4 \\
2 & 0.324 & 51 & X52 & 0.8 & 0.56 & 2 \\
3 & 0.324 & 71.5 & X60 & 0.4 & 0.405 & 3 \\
4 & 0.324 & 92 & X52 & 0.8 & 0.25 & 2 \\
5 & 0.324 & 92 & X52 & 0.8 & 0.56 & 4 \\
6 & 0.543 & 51 & X60 & 0.4 & 0.405 & 3 \\
7 & 0.543 & 71.5 & X52 & 0.4 & 0.405 & 3 \\
8 & 0.543 & 71.5 & X60 & 0.4 & 0.25 & 3 \\
9 & 0.543 & 71.5 & X60 & 0.4 & 0.405 & 2 \\
10 & 0.543 & 71.5 & X60 & 0.4 & 0.405 & 3 \\
11 & 0.543 & 71.5 & X60 & 0.4 & 0.405 & 4 \\
12 & 0.762 & 51 & X70 & 0.8 & 0.56 & 2 \\
13 & 0.762 & 71.5 & X60 & 0.4 & 0.405 & 3 \\
14 & 0.762 & 92 & X70 & 0.8 & 0.25 & 2 \\
15 & 0.762 & 92 & X70 & 0.8 & 0.56 & 4 \\
\hline
\end{tabular}

Tables 8 and 9 for 15 unpressurized and 15 pressurized cases, respectively. A comparison of the engineering expression defining the compressive strain capacity (eq. [2]) and the FE simulations is shown in Fig. 13. The results show excellent correspondence with small residual error.

As shown in Fig. 14, for the unpressurized cases, the strain capacity was strongly influenced by the linear, $D / t$, and quadratic terms, $(D / t)^{2}$, for the diameter to wall thickness ratio. The yield strength to elastic modulus ratio (SMYS/E), pipe diameter $(D)$, and axial load to plastic axial section force ratio $(\alpha)$ have the smallest contributions for the parameters examined. The same trends were observed for the 15 pressurized cases examined (Fig. 15) with the hoop stress design factor, $\beta$, also being significant. The hoop stress design factor relates the hoop stress in the pipe wall due to internal pressure with the circumferential yield strength of the pipe wall material.

The compressive strain capacity estimates for pipe with in-air boundary conditions, using the third-party strain capacity equations of Dorey (2001), Gresnigt (1986), and Zimmerman et al. (1995), were compared with the FE simulations conducted in this study for unpressurized (Fig. 16) and pressurized (Fig. 17) buried pipelines. The pipeline stress-strain relationship was considered to be roundhouse-type behaviour and the blister imperfection 
Fig. 13. Comparison between current study's predictions in terms of critical strain versus continuum finite element analysis.

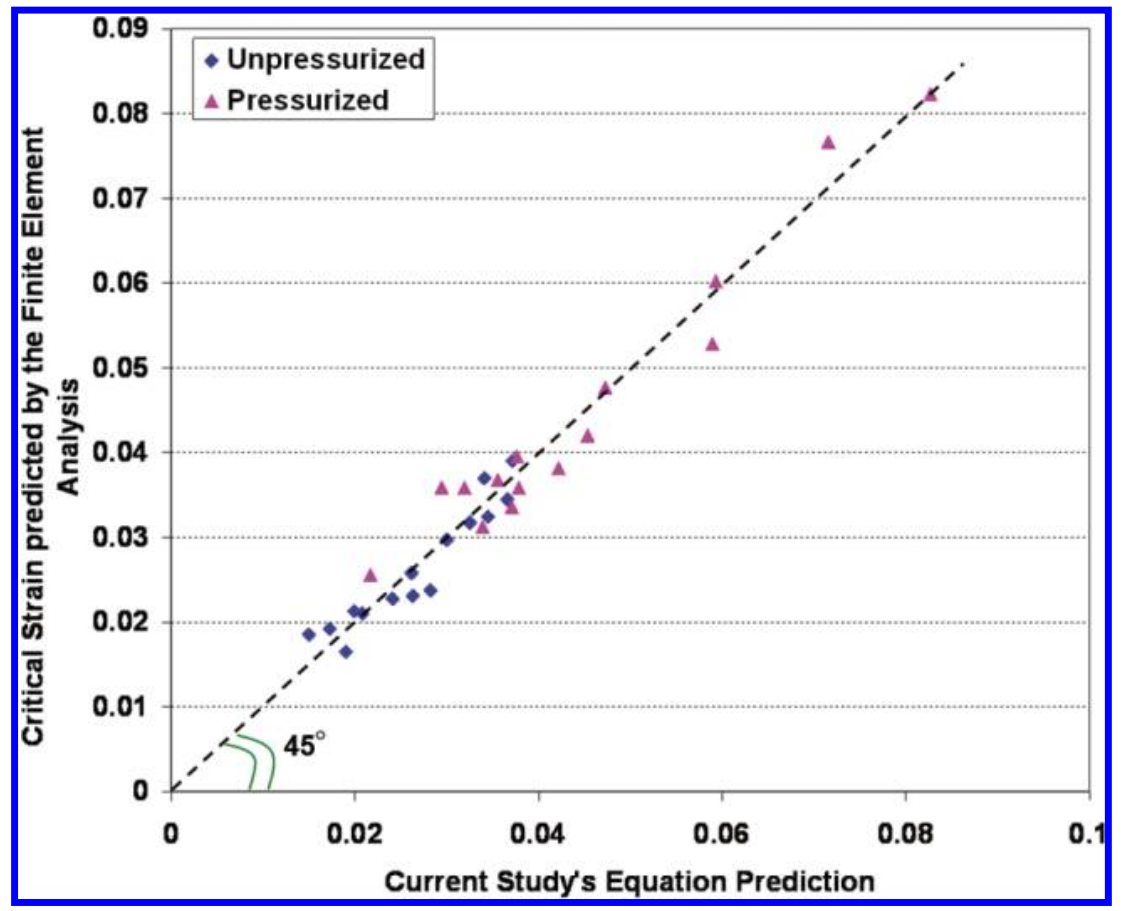

Fig. 14. Current study's equation's terms contributions to the response - unpressurized cases.

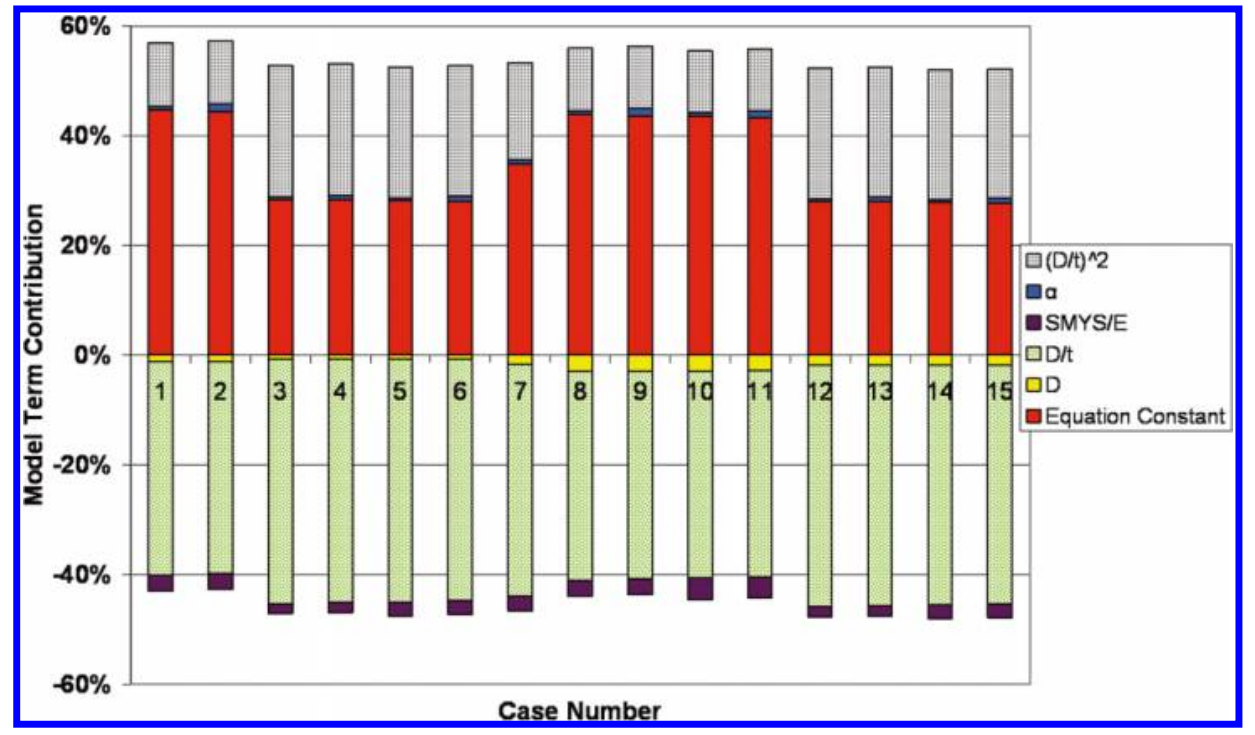

amplitude was $2 \%$ of the pipe wall thickness. The critical strain estimates for pipe segments in-air was lower than the corresponding strain capacity simulations for buried pipe by a factor of $0.2-$ 0.6. The strain capacity estimates using Dorey's (2001) expression may be more consistent with the buried pipe strain predictions as the study parameters and ranges are similar.

As the internal pressure decreases, there is a larger discrepancy between the strain capacity estimates for in-air pipe based on third-party studies with the numerical simulations for buried pipe as conducted in this study. For in-air pipe segments, as the internal pressure increases there is a reduction in the pipe moment capacity and increase in the pipe strain capacity (Fatemi et al. 2008). This can be attributed to stress space on the von Mises yield surface, with respect to strength, and stiffening effects on section ovalization with respect to curvature and local buckling response. Furthermore, a complex interaction and competition between deformation modes (i.e., section ovalization, bifurcation, and longitudinal waveform) evolves during bending that can be influenced by pipeline length, end boundary conditions, $D / t$, and level of internal pressure (Fatemi et al. 2008, 2010; Fatemi and Kenny 2011, 2012). Other factors that may contribute to the scatter in the response (Figs. 16 and 17) may include variability in study parameters and techniques to estimate critical strain.

A significant factor implicit in the observed response is pipesoil interaction effects. The soil or ground restraint (i.e., forces, moments) imposes ground curvature on the pipe leading to the evolution of a different pipe mechanical response (i.e., section ovalization and the onset of local bucking mechanisms) in comparison with conventional engineering assessments based on inair boundary conditions. This can be observed by comparing the moment-curvature response of buried pipelines (Figs. 5 and 9) 
Fig. 15. Ccurrent study's equation's terms contributions to the response - pressurized cases.

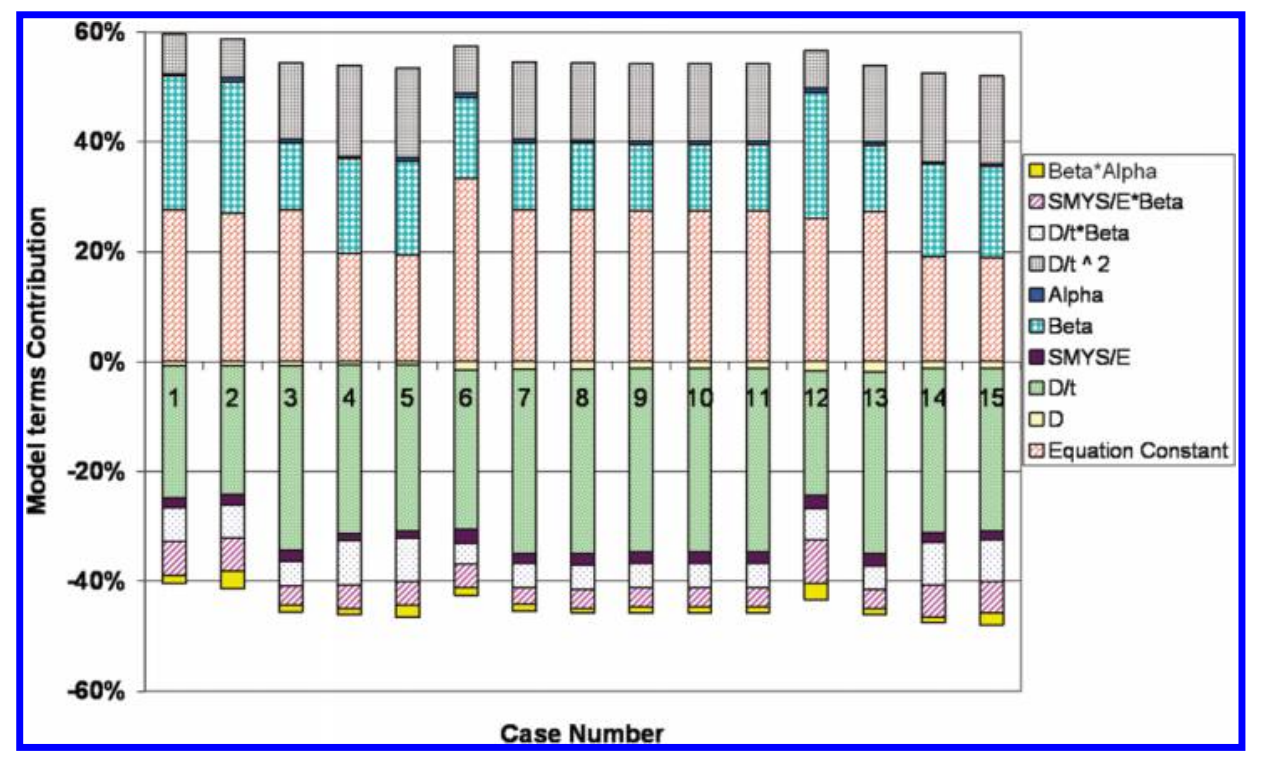

Fig. 16. Comparison between in-air based criteria in the literature (Dorey 2001; Zimmerman et al. 1995; CSA 2003) and FE results for buried pipes - unpressurized cases.

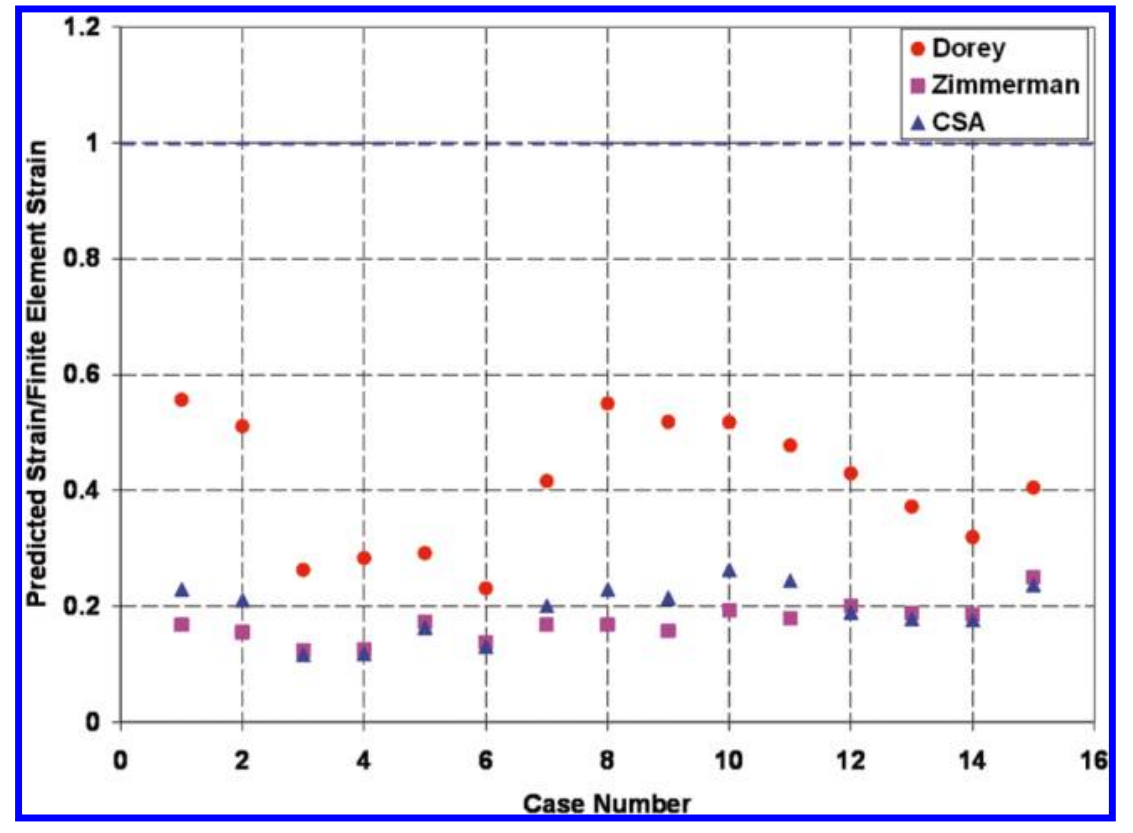

with the in-air pipe (Fig. 12). Because of interaction effects, the pipeline and soil act like a composite section, which provides larger bending resistance for the pipe-soil system than a pipeline in-air. Soil supports part of the external forces imposed on the pipe. Figure 18 illustrates the simplified force diagram acting on a buried pipe in the pipe-soil interaction numerical model. The bending moment due to applied external forces (initial axial force $(N)$ and lateral force $(F)$ ) is called applied moment $\left(M^{\mathrm{N}, \mathrm{F}}\right)$. The bending moment measured at the pipeline's critical section is called sectional moment $(M)$. Comparison of the pipeline applied and sectional moment at the critical section for analysis 10 (Table 9) is illustrated in Fig. 19. The difference between the two diagrams is supported by the surrounding soil (designated $R_{s} c$ in Fig. 18). Soil restraint has other effects on local buckling response of buried pipeline that cannot be captured through in-air based modeling. Soil pressure moderates moment-curvature, ovality-curvature response of a pipeline in comparison with in-air based results.
Palmer et al. (1990) showed the beneficial effect of soil support to mitigate upheaval buckling. A semiempirical method was developed, for use in preliminary engineering design, to estimate the required soil download pressure to prevent upheaval buckling of a buried pipeline subject to effective axial forces. The study concluded that a slight increase in soil resistance can significantly increase the axial load needed to cause upheaval buckling (Fig. 20). The driving force for upheaval buckling increases with greater temperature differential due to thermal expansion. As shown in Fig. 20, the abscissa defines the amount of pipeline uplift before buckling occurs corresponding to a certain depth cover. Although the study by Palmer et al. (1990) focused on upheaval buckling and not local buckling of buried pipelines, there are common attributes and correlations. The key aspect is the effect of soil support on the evolution of pipe curvature from the initial global bending response through the initiation of local buckling mechanisms can be correlated with the upheaval 
Fig. 17. Comparison between in-air based criteria in the literature (Dorey 2001; Zimmerman et al. 1995; CSA 2003) and current study's results for buried pipes - pressurized cases.

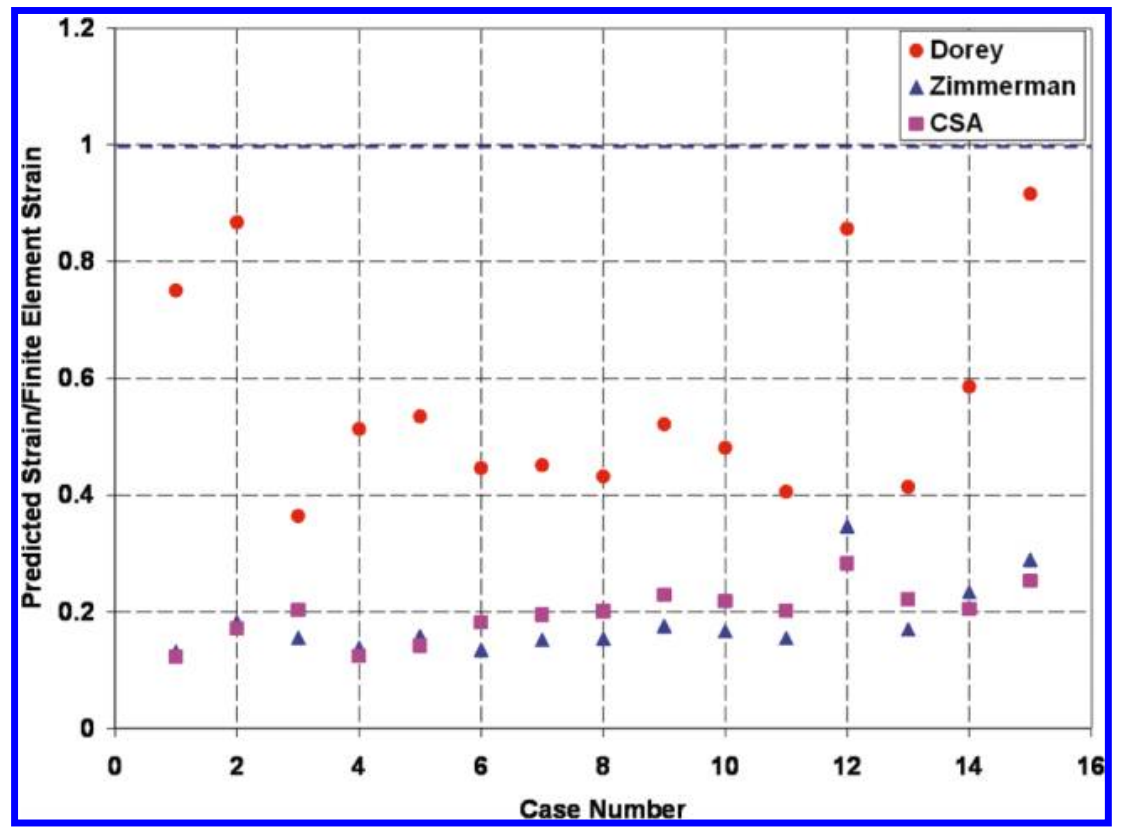

Fig. 18. Simplified force diagram of the buried pipeline in current study's numerical model.

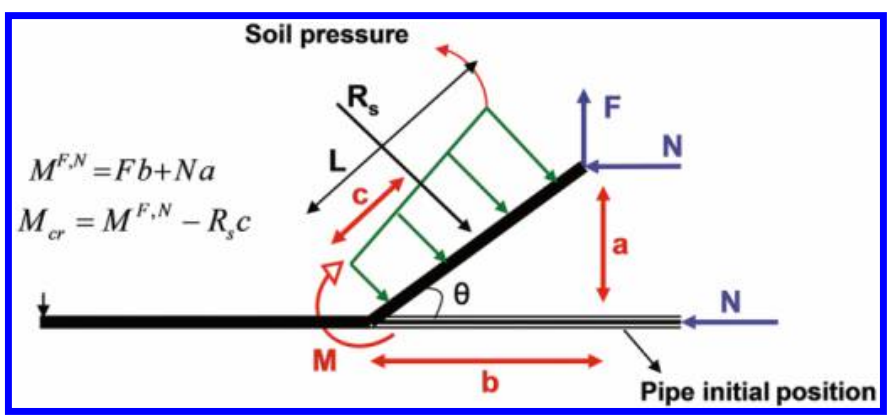

Fig. 19. Applied and sectional moment comparison (case 10 from Table 9).

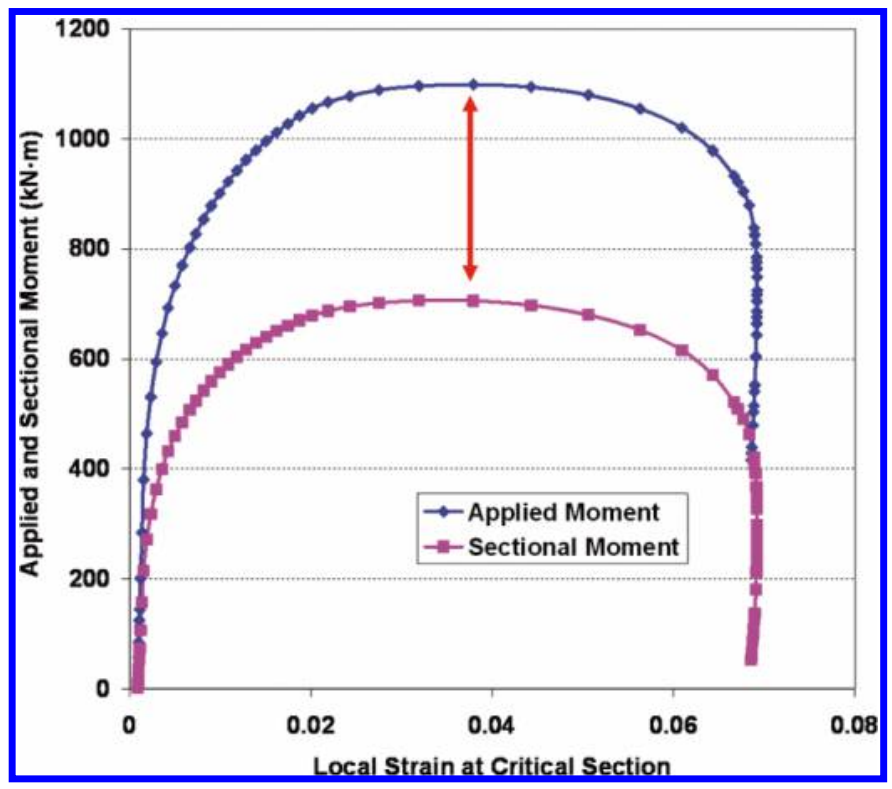

Fig. 20. Soil resistance and axial force effects on upheaval buckling (modified after Palmer et al. 1990).

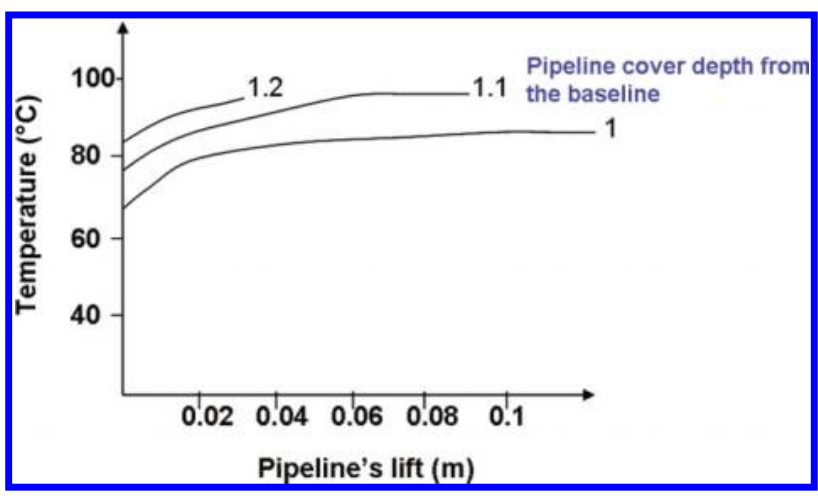

buckling studies conducted by Palmer et al. (1990), which are further discussed by Mahdavi et al. (2010).

\section{Conclusion}

A continuum FE model was developed and calibrated based on large-scale test results from both in-air and buried pipeline tests to study the local buckling behaviour of the buried pipelines. The FE software ABAQUS/Standard was used to develop the numerical modeling procedures. A comprehensive parametric study was conducted to study the effect of six parameters (pipeline external diameter, pipeline diameter over thickness ratio, pipeline grade, internal pressure, axial force, and burial depth over diameter) on the critical buckling strain of pipelines buried in firm clay. A new critical strain equation for buried pipelines was developed and evaluated. Results of the parametric study are presented in this paper.

The surrounding soil has a restraining effect, which increases the effective pipeline bending resistance and curvature at peak moment, when the pipeline is subjected to large displacementcontrolled geotechnical loads. Because of pipeline-soil interaction effects, the soil reacts to some of the external forces imposed on the pipe itself. This soil restraining effect is ignored when 
conventional engineering practices based on in-air criteria are used to predict the critical strain for buried pipes.

The predicted critical strains for buried pipes, based on the numerical simulations conducted in this study, are compared with several critical strain equations available in the open literature that consider only in-air boundary conditions. The in-air based criteria predicted lower critical strain estimates, for pressurized and unpressurized pipe, in comparison with the strain capacity estimates for buried pipelines based on the numerical simulations conducted in this study. The strain capacity equation presented in this study is not intended for use in engineering design. Physical tests are required to validate the numerical observations. The critical strain capacity equation is presented in this study to provide a quantitative assessment tool that can account for the effect of the surrounding soil on the pipe section ovalization and moment response in comparison with conventional engineering practice based on in-air boundary conditions.

\section{Acknowledgments}

The authors wish to acknowledge Dr. L.M. Lye of the Department of Engineering at the Memorial University of Newfoundland for his advice and guidance on the design of experimental applications in the research. The financial support of the Natural Sciences and Engineering Research Council (NSERC), C-CORE, and Wood Group Chair in Arctic and Harsh Environments Engineering at Memorial University of Newfoundland is greatly appreciated.

\section{References}

Bruschi, R., Monti, P., Bolzoni, G., and Tagliaferri, R. 1995. Finite element method as numerical laboratory for analysing pipeline response under internal pressure, axial load, bending moment. Proceedings of the Offshore Mechanics and Arctic Engineering (OMAE), Vol. 5, pp. 389-401.

Bughi, S., Aleotti, P., Bruschi, R., Andrei, G., Milani, G., Scarpelli, G., and Sakellariadi, E. 1996. Slow movements of slopes interfacing with pipelines: modelling and monitoring. Proceedings of the Offshore Mechanics and Arctic Engineering (OMAE), Florence, Italy, Vol. 5, pp. 363-372.

CSA. 2003. Oil and gas pipeline systems. CSA standard CSA Z662 2003. Canadian Standards Association.

DNV. 2010. Submarine pipeline systems. DNV standard DNV-OS-F101. Det Norske Veritas.

Doblanko, R.M. , Fladoger, S.J., and Wilkie, S.A. 2001. Permafrost pipelining. 1: Northern Canadian pipeline deals with soil movement. Oil \& Gas Journal, 99(5), p. 13.

Dorey, A.B. 2001. Critical buckling strains for energy pipelines. Ph.D. thesis, Department of Civil and Environmental Engineering, University of Alberta, Edmonton, Alberta.

Fatemi, A., and Kenny, S. 2011. Continuum modelling framework for local buckling response of plain and girth welded pipes. Proceedings, OTC-21998-PP.

Fatemi, A., and Kenny, S. 2012. Characterization of initial geometric imperfections for pipelines and influence on compressive strain capacity. Proceedings, ISOPE, Vol. IV, pp. 550-556.

Fatemi, A., Kenny, S., Sen, M., Zhou, J., Taheri, F., and Paulin, M. 2008. Investigations on the local buckling response of high strength linepipe. Proceedings, IPC2008-64407.

Fatemi, A., Kenny, S., Taheri, F., Duan, D-M., and Zhou, J. 2010. End boundary effects on the local buckling response of high strength linepipe. Proceedings, IPC2010-31397.

Glover, A., Zhou, J., and Blair, B. 2002. Technology approaches for northern pipeline developments. Proceedings of International Pipeline Conference (IPC), Calgary, Alberta, pp. 503-515.

Gresnigt, A.M. 1986. Plastic design of buried steel pipelines in settlement areas. Heron, 31(4).

Grivas, D.A., Bhagvati, C., Schultz, B.C., McGuffey, V.C, O'Neil, G.D., and Simmonds, G.R. 1996. Achieving reliable designs for pipelines traversing unstable slopes. Proceedings of the Specialty Conference on Pipeline Crossings, Burlington, Vt., pp. 426-433.

Honegger, D.G., and Nyman, J. 2004. Guidelines for the seismic design and assessment of natural gas and liquid hydrocarbon. Pipelines Research Council International Project PR-268-9823.
Kenny, S., Barrett, J., Phillips, R., and Popescu, R. 2007. Integrating geohazard demand and structural capacity modelling within a probabilistic design framework for offshore arctic pipelines. Proceedings of the International Offshore and Polar Engineering Conference, Lisbon, Portugal, pp. 3057-3064.

Konuk, I., Phillips, R., Hurley, S., and Paulin, M.J. 1999. Preliminary ovalisation of buried pipeline subjected to lateral loading. Proceedings of the Offshore Mechanics and Arctic Engineering (OMAE), St. John's, N.L.

Kulhawy, F.H., and Mayne, P.W. 1990. Manual on estimating soil properties for foundation design. Electric Power Research Institute, Palo Alto, Calif.

Kyriakides, S., and Corona, E. 2007. Mechanics of offshore pipelines: Vol. I Buckling and collapse. Elsevier.

Mahdavi, H., Kenny, S., Phillips, R., and Popescu, R. 2008. Influence of geotechnical loads on local buckling behaviour of buried pipelines. Proceedings of International Pipeline Conference (IPC), Calgary, Alberta, Vol. 3, pp. 543-551.

Mahdavi, H., Kenny, S., Phillips, R., and Popescu, R. 2009a. Comprehensive parametric study on local buckling response of buried pipelines. Proceedings, Canadian Society for Civil Engineering Annual Conference (CSCE), St. John's, N.L., Vol. 1, pp. 177-186.

Mahdavi, H., Kenny, S., Phillips, R., and Popescu, R. 2009b. Effect of embedment ratio on buried pipelines subject to combined loading. Proceedings of 62nd Canadian geotechnical conference, GeoHalifax2009, Halifax, Nova Scotia.

Mahdavi, H., Kenny, S., Phillips, R., and Popescu, R. 2010. Effect of soil restraint on the buckling response of buried pipelines. Proceedings, International Pipeline Conference (IPC), Calgary, Alberta, Paper IPC2010-31617.

Mohareb, M., Kulak, G.L., Elwi, A., and Murray, D.W. 2001. Testing and analysis of steel pipe segments. Journal of Transportation Engineering, 127(5): 408-417. doi:10.1061/(ASCE)0733-947X(2001)127:5(408).

Montgomery, D.C. 2005. Design and analysis of experiments. 6th ed. John Wiley and Sons, Inc., Hoboken, New Jersey.

Morgan, V., Kenny, S., Power, D., and Gailing, R. 2004. Monitoring and analysis of the effects of ground movement on pipeline integrity. Proceedings of International Conference on Terrain and Geohazard Challenges facing Onshore Oil and Gas Pipelines, London, United Kingdom, pp. 701-712.

Murphey, C.E., and Langner, C.G. 1985. Ultimate pipe strength under bending, collapse and fatigue. Proceedings of the Offshore Mechanics and Arctic Engineering (OMAE), Dallas, Tex., pp. 467-477.

Palmer, A.C., Ellinas, C.P., Richards, D.M., and Guijt, J. 1990. Design of submarine pipelines against upheaval buckling. Proceedings of the 22nd Annual Offshore Technology Conference (OTC), Houston, p. 10.

Paulin, M.J., Phillips, R., Trigg, A., and Konuk, I. 1998a. A full-scale investigation into pipeline/soil interaction. Proceedings of International Pipeline Conference (IPC), Calgary, Alberta, Vol. 2, pp. 779-787

Paulin, M.J., Hurley, S., and Phillips, R. 1998b. Summary report - full scale pipe/ soil interaction study; lateral loading in clay. Contract Report for NOVA Gas Transmission Limited and the Geological Survey of Canada, C-CORE Publication 98-C17, St. John's, N.L.

Peek, R. 2000. Axisymmetric wrinkling of cylinders with finite strain. Journal of Engineering Mechanics, 126(5): 455-461. doi:10.1061/(ASCE)07339399(2000)126:5(455)

Popescu, R., Phillips, R., Konuk, I., Guo, P., and Nobahar, A. 2002a. Pipe-soil interaction: large scale tests and numerical modelling. Proceedings of International Conference of Physical Modelling in Geotechnic, St. John's, N.L., pp. 917-922.

Popescu, R., Konuk, I., Guo, P., and Nobahar, A. 2002b. Some aspects in numerical analysis of pipe-soil interaction. Proceedings of the 2nd Canadian Specialty Conference on Computer Application in Geotechnique, Winnipeg, Man.

Sherman, D. 1976. Tests of circular steel tubes in bending. Journal of the Structural Division, ASCE, 102(11): 2181-2195.

Suzuki, N., Kondo, J., Endo, S., Ishikawa, N., Okatsu, M., and Shimamura, J. 2006. Effects of geometric imperfection on bending capacity of X80 linepipe. Proceedings, IPC, Paper No. IPC2006-10070.

Terzaghi, K., and Peck, R.B. 1967. Soil mechanics in engineering practice, 2nd ed. John Wiley and Sons.

Vitali, L., Bruschi, R., Mork, K.J., Levold, E., and Verley, R. 1999. Hotpipe project capacity of pipes subject to internal pressure, axial force and bending moment. Proceedings of the International Offshore and Polar Engineering Conference, Golden, Colo., Vol. 2, pp. 22-33.

Walker, A.C., and Williams, K.A.J. 1995. Strain based design of pipelines. Proceedings of the International Offshore and Arctic Engineering Conference (OMAE), Copenhagen, Denmark, Vol. 5, pp. 345-350.

Zimmerman, T.E, Stephens, M.J., DeGeer, D.D, and Chen, Q. 1995. Compressive strain limits for buried pipelines. Proceedings of the International Offshore and Arctic Engineering Conference (OMAE), Copenhagen, Denmark, Vol. 5, pp. 365-378. 